\title{
High Nitrogen Levels Alleviate Yield Loss of Super Hybrid Rice Caused by High Temperatures During the Flowering Stage
}

\author{
Ke Liu'1,2, Jun Deng ${ }^{1}$, Jian Lư ${ }^{1}$, Xiaoyan Wang ${ }^{1,2}$, Bilin $L u^{1,2}$, Xiaohai Tian ${ }^{1,2}$ and \\ Yunbo Zhang ${ }^{1,2 *}$
}

${ }^{1}$ Hubei Collaborative Innovation Center for Grain Industry, Yangtze University, Jingzhou, China, ${ }^{2}$ College of Agriculture, Yangtze University, Jingzhou, China

OPEN ACCESS

Edited by:

Meixue Zhou,

University of Tasmania, Australia

Reviewed by:

Chengdao Li,

Murdoch University, Australia

Wanju Shi,

Hunan Agricultural University, China

*Correspondence:

Yunbo Zhang

yunbo1022@126.com

Specialty section:

This article was submitted to

Plant Abiotic Stress,

a section of the journal

Frontiers in Plant Science

Received: 09 December 2018

Accepted: 07 March 2019

Published: 26 March 2019

Citation:

Liu K, Deng J, Lu J, Wang X,

Lu B, Tian X and Zhang Y (2019) High

Nitrogen Levels Alleviate Yield Loss

of Super Hybrid Rice Caused by High

Temperatures During the Flowering

Stage. Front. Plant Sci. 10:357.

doi: 10.3389/fp/s.2019.00357
The effect of high temperatures on rice production has attracted considerable research attention. It is not clear, however, whether nitrogen $(\mathrm{N})$ management can be used to alleviate the damaging effects of high temperatures on flowering in rice. In this study, we compared the yields of five elite super hybrid rice varieties and examined their heat tolerance under four $\mathrm{N}$ treatments in two seasons with contrasting temperatures at flowering: 2015 (normal temperature) and 2016 (high temperature). The average daily temperature during the flowering stage in 2016 was $31.1^{\circ} \mathrm{C}$, which was $4.5^{\circ} \mathrm{C}$ higher than that in 2015. There was a significant positive correlation between grain yield and $\mathrm{N}$ level $\left(R^{2}=0.42, P<0.01\right)$. However, mean grain yield of the five rice varieties in 2015 was $10.5 \%$ higher than that in 2016 . High $N$ levels reduced yield losses in plants exposed to high temperature in 2016. The mean seed-set percentage in 2016 was 13.0\% lower than that in 2015 at higher $\mathrm{N}$ levels, but spikelets per panicle increased by $7.6 \%$ at higher $\mathrm{N}$ levels compared with lower $\mathrm{N}$ levels. Higher $\mathrm{N}$ levels reduced the number of degenerated spikelets under high temperatures. Spikelets per panicle and $\mathrm{N}$ treatment level were positively correlated at high temperatures $\left(R^{2}=0.32, P<0.05\right)$. These results confirmed that increasing $N$ application could alleviate yield losses caused by high temperatures in super hybrid rice during the flowering stage.

Keywords: super hybrid rice, nitrogen, high temperature, grain yield, heat stress, climate change

\section{INTRODUCTION}

Mean global temperatures are forecast to rise by as much as $2^{\circ} \mathrm{C}$ by the middle of the 21 st century, with a concurrent increase in the frequency and intensity of extreme heat waves (Intergovernmental Panel on Climate Change [IPCC], 2013). Piao et al. (2010) reported that temperatures have increased by $0.15-0.40^{\circ} \mathrm{C}$ every 10 years over the past 50 years in China. As the largest rice producer in the world, China contributes nearly thirty percent of global rice production (Food and Agriculture Organization [FAO], 2010; Seck et al., 2012). Rice cultivars in China are increasingly exposed to extremely high temperatures with ongoing climate change. For example, temperatures of $35^{\circ} \mathrm{C}$-significantly exceeding the critical threshold temperature $\left(33^{\circ} \mathrm{C}\right)$ for growing rice (Bheemanahalli et al., 2016; Liu et al., 2017)-that lasted for more than half a month, contributed to an estimated total yield loss of $5.18 \times 10^{7} \mathrm{t}$ in the Yangtze Valley, resulting in significant economic losses in 2003 (Tian et al., 2009). The annual planting area of hybrid rice has increased to about 
15 million ha in recent years, accounting for more than $50 \%$ of the total rice planting area in China (Cheng et al., 2007). The super hybrid rice cultivars that have made significant contributions to the increase in yields in China (Peng et al., 2008) are predominant in the Yangtze Valley. It is crucial, therefore, to alleviate the effects of heat stress on rice production in this area to maintain food security in China.

Flowering is considered the most susceptible stage of development to high-temperature stress in rice plants (Satake and Yoshida, 1978; Farrell et al., 2006). Temperatures over $35^{\circ} \mathrm{C}$ for more than $1 \mathrm{~h}$ during flowering can lead to significant declines in spikelet fertility; a negative correlation between spikelet fertility and cumulative temperature over $34^{\circ} \mathrm{C}$ in rice plants was observed by Jagadish et al. (2007). Shorter grain filling durations caused by high temperatures were due to the loss of sink activity owing to earlier senescence of the panicle (Kim et al., 2011). Previous studies have indicated that an increase in spikelet sterility caused by high-temperature stress was caused by abnormal anther dehiscence (Matsui and Omasa, 2002), glume closure (Yan et al., 2017) and impaired pollination (Matsui et al., 2005) and pollen germination (Jagadish et al., 2009). In the Yangtze Valley, Tian et al. (2009) observed that a maximum temperature of approximately $35^{\circ} \mathrm{C}$ or daily mean temperature of $30^{\circ} \mathrm{C}$ (with relative humidity of approximately $70 \%$ and low wind speeds) lasting for more than 3 days during the flowering period, led to significant seed-set losses in rice plants.

Some previous studies have shown that plant nutrients play a vital role in improving tolerance to temperature stress and that proper nitrogen management can partially mitigate the damaging effects of high temperature on crops (Waraich et al., 2012). A high $\mathrm{N}$ rate at panicle initiation or flowering was shown to alleviate the detrimental effects of high temperature on grain yield (Dai et al., 2009; Duan et al., 2013; Yang et al., 2014). One possible reason for this is that $\mathrm{N}$ application reduced the rice canopy temperature by contributing to a better rice canopy structure with a high leaf area index (LAI), which facilitated higher transpiration cooling (Yan et al., 2008). However, Shi et al. (2017) reported that increasing total $\mathrm{N}$ fertilizer application did not alleviate the adverse effects of high night temperatures on rice yield. These results may be controversial in some cases as most results were obtained from climate chambers instead of field conditions. Little information is available about the effects of $\mathrm{N}$ in combination with hightemperature exposure on rice yields under field conditions. In this study, field experiments were carried out with the following objectives: (1) verify the beneficial effects of high $\mathrm{N}$ levels on grain yield under high temperatures and paddy conditions; (2) compare the yields of five elite super hybrid rice varieties under four $\mathrm{N}$ treatments; and (3) identify the key factors that influence grain yield of rice under high $\mathrm{N}$ conditions, when plants are subjected to high temperatures at the flowering stage.

\section{MATERIALS AND METHODS}

The study consisted of two experiments. Pot experiments were used to investigate the heat tolerance of different rice varietals, and field experiments were used to verify the effects of high $\mathrm{N}$ on grain yields of super hybrid rice cultivars under conditions of high temperature during the flowering period.

\section{Pot Experiments}

Five super hybrid rice cultivars (Table 1), were used in this study. Seeds of these cultivars were germinated at room temperature $\left(25^{\circ} \mathrm{C}\right)$ during the second half of April. After 20 days, 25-30 rice seedlings of similar height were transferred into plastic pots (30 $\mathrm{cm}$ height and $30 \mathrm{~cm}$ diameter). For each pot, $12.5 \mathrm{~kg}$ of soil was mixed with $8 \mathrm{~g}$ of composed fertilizer (with a ratio of 26:10:15 N:P:K) and then filled with water. Only the main stem was kept. Pots were then cultivated at the experimental farm of Yangtze University, Jingzhou City, Hubei Province, China $\left(112^{\circ} 31^{\prime} \mathrm{E}, 30^{\circ} 21^{\prime} \mathrm{N}\right)$.

At the anthesis stage, rice plants were exposed to hightemperature treatments for 3 days, as follows. 1 day before anthesis, the rice plants were moved into a growth chamber (Conviron Company, PGW40, Winnipeg, MB, Canada) to start heat treatment with a 14:10 h day:night cycle and a $2 \mathrm{~h}$ change in the temperature simulating typical local heat stress, following the protocol of $\mathrm{Mu}$ et al. (2017). For the control and hightemperature treatments, temperatures were set as shown in Table 2; the actual temperature regimes were $27^{\circ} \mathrm{C}$ (normal), and $30^{\circ} \mathrm{C}$ (high) average temperature, and their corresponding daily maximum temperatures were 31 and $33^{\circ} \mathrm{C}$. The relative humidities were 70 and $80 \%$ for day and night, respectively.

To examine the seed-set percentage, panicles were sampled 1 month after heat-stress treatment. Twenty panicles were sampled from each pot and their seed sets were examined by manual inspection of ovary development.

\section{Field Experiments}

Field experiments were conducted at the experimental farm of Yangtze University in 2015 and 2016. Soil samples from the upper $20 \mathrm{~cm}$ were taken before the experiments and soil properties were tested following the protocol of $\mathrm{Lu}$ (1999). The soil of the experimental site was calcareous alluvial with the following properties: $\mathrm{pH} 6.8,18.5 \mathrm{~g} \mathrm{~kg}^{-1}$ organic matter, $110.5 \mathrm{mg} \mathrm{kg}^{-1}$ alkali-hydrolysable $\mathrm{N}, 25.0 \mathrm{mg} \mathrm{kg}^{-1}$ available P, and $105.5 \mathrm{mg} \mathrm{kg}^{-1}$ available $\mathrm{K}$. Data for the soil properties were averaged across the 2 years.

Treatments were arranged in a split-plot design with $\mathrm{N}$ treatments as the main plots and cultivars as the subplots. The experiment was replicated three times, and the subplot size was $30 \mathrm{~m}^{2}$. The four $\mathrm{N}$ treatments were applied as follows: $0 \mathrm{~kg} \mathrm{ha}^{-1}$

TABLE 1 | Information about rice varieties used in the experiment.

\begin{tabular}{lcccc}
\hline Variety & Type & Year of release & Female parent & Male parent \\
\hline LYPJ & Intermediate $^{a}$ & 1999 & Pei'ai64S & Yangdao 6 \\
YLY1 & Indica & 2006 & Y58S & Yangdao 6 \\
YLY 2 & Indica & 2006 & Y58S & Yuanhui 2 \\
YLY 900 & Indica & 2015 & Y58S & R900 \\
S1000 & Indica & Unreleased & Guangxiang24S & R900 \\
\hline
\end{tabular}

a The intermediate type between indica and japonica. 
TABLE 2 | Day/night temperature settings $\left({ }^{\circ} \mathrm{C}\right)$ of growth chambers for different heat treatments.

\begin{tabular}{ll}
\hline Treatment & Time (hh:mm)
\end{tabular}

$\begin{array}{llllllllllllllllllllllllll}21: 00 & 22: 00 & 23: 00 & 0: 00 & 1: 00 & 2: 00 & 3: 00 & 4: 00 & 5: 59 & 6: 00 & 7: 00 & 8: 00 & 9: 00 & 10: 00 & 11: 00 & 12: 00 & 13: 00 & 14: 00 & 15: 00 & 16: 00 & 17: 00 & 18: 00 & 19: 00 & 20: 01\end{array}$

\begin{tabular}{llllllllllllllllllllllllllllllll}
\hline $\begin{array}{l}\text { Normal } \\
\text { temperature }\end{array}$ & 28 & 28 & 27 & 26 & 26 & 25 & 25 & 25 & 25 & 25 & 26 & 26 & 27 & 28 & 29 & 30 & 30 & 31 & 31 & 30 & 30 & 29 & 29 & 28 \\
$\begin{array}{l}\text { High } \\
\text { temperature }\end{array}$ & 30 & 30 & 29 & 29 & 28 & 28 & 27 & 27 & 27 & 27 & 28 & 28 & 30 & 30 & 32 & 32 & 33 & 33 & 32 & 32 & 31 & 31 & 30 & 30
\end{tabular}

(N1), $210 \mathrm{~kg} \mathrm{ha}^{-1}$ (N2), $300 \mathrm{~kg} \mathrm{ha}^{-1}$ (N3), and $390 \mathrm{~kg} \mathrm{ha}^{-1}$ (N4). Nitrogen fertilizer was applied at the basal, tillering, and panicle stages in a ratio of 5:2:3. For the $\mathrm{N} 2$ treatment, 105,42 , and $63 \mathrm{~kg}$ $\mathrm{N} \mathrm{ha}^{-1}$ were applied at the baseline (1 day before transplanting), early tillering (7 days after transplanting), and panicle initiation stages (the first appearance of a differentiated apex), respectively. For the N3 and N4 treatments, 150,60, and $90 \mathrm{~kg} \mathrm{~N} \mathrm{ha}^{-1}$ and 195, 78 , and $117 \mathrm{~kg} \mathrm{~N} \mathrm{ha}^{-1}$ were applied at the baseline, early tillering, and panicle initiation stages, respectively.

Five super hybrid rice cultivars were used in the experiments (Table 1). Pre-germinated seeds were sown in a seedbed at ate of $25 \mathrm{~g} \mathrm{~m}^{-2}$. Thirty to 32-day-old seedlings were transplanted, with a hill spacing of $20 \times 30 \mathrm{~cm}$ and two seedlings per hill. Phosphorus (105 kg ha ${ }^{-1}$ ) was applied and incorporated in all subplots 1 days before transplanting. Potassium (210, 300, and $390 \mathrm{~kg} \mathrm{ha}^{-1}$ ) was split equally between the basal and panicle initiation stages under N2, N3, and N4, respectively. Crop management followed standard cultural practices. Insects were intensively controlled by chemicals to avoid biomass and yield losses.

Twelve hills were sampled diagonally from a $5 \mathrm{~m}^{2}$ harvest area in each subplot at maturity. For all sampling, the three border lines were excluded to avoid border effects. Plants were hand threshed after the panicles were counted. Filled spikelets were separated from unfilled spikelets by submerging them in tap water. Three subsamples of $30 \mathrm{~g}$ filled grains and all unfilled spikelets were removed to count the number of spikelets. The filled and unfilled spikelets were determined after oven drying at $70^{\circ} \mathrm{C}$ to a constant weight. Spikelets per panicle and seed-set percentage $(100 \times$ filled spikelet number/total spikelet number $)$ were calculated. Grain yield was determined from a $5 \mathrm{~m}^{2}$ area in the middle of each subplot and adjusted to a moisture content of $0.14 \mathrm{~g} \mathrm{H}_{2} \mathrm{O} \mathrm{g}^{-1}$ fresh weigh.

To address the yearly experimental variation and measure the changes in yield production caused by $N, \Delta G$ was used to represent the grain yield production increase from using $\mathrm{N}$, calculated as follows:

$$
\Delta \mathrm{G}_{\mathrm{N} i}=\text { Mean grain yield in } \mathrm{N} i-\text { mean grain yield in N1, }
$$

where $i$ is treatment 2, 3, or 4 .

To test the effects of cultivars, treatments, year, and their interaction effects on grain yield and yield components, statistical analysis was carried out using a three-way analysis of variance (ANOVA) using SAS software (SAS Institute Inc., Cary, NC, United States); a least significant difference (LSD) test was used to compare the means.

\section{RESULTS}

\section{Heat Tolerance of the Tested Cultivars}

The cultivars responded differently to high-temperature treatment. Seed-set percentages for all cultivars, except YLY1, were significantly reduced by high temperature (Figure 1). There was a $24.4 \%$ difference in seed set in LYPJ between normal and high temperature, 21.9\% in YLY2, 20.2\% in YLY900, and 26.2\% in S1000. YLY1 did not show any significant change in seed set under high temperature, which suggests that YLY1 was the most tolerant to heat stress among these cultivars.

\section{Temperature Differences in 2015 and 2016 During the Flowering Period}

For the period 2001-2016, the summer mean temperature was $26.3^{\circ} \mathrm{C}$ (Figure 2A). Among these years, only four had temperatures below the historical seasonal mean, which were 2004, 2011, 2014, and 2015. In 2015, the seasonal mean temperature was only $25.7^{\circ} \mathrm{C}$ but in some years it was extremely high. The fourth highest seasonal mean temperature was $26.8^{\circ} \mathrm{C}$ in 2016. Daily average temperatures during the growing season in 2016 were $1.0^{\circ} \mathrm{C}$ higher than those in 2015 (Figure 2B). The daily mean temperature during the flowering period in 2016 was $31.2^{\circ} \mathrm{C}$, compared to $26.7^{\circ} \mathrm{C}$ in 2015 . There was a $3.4 \%$

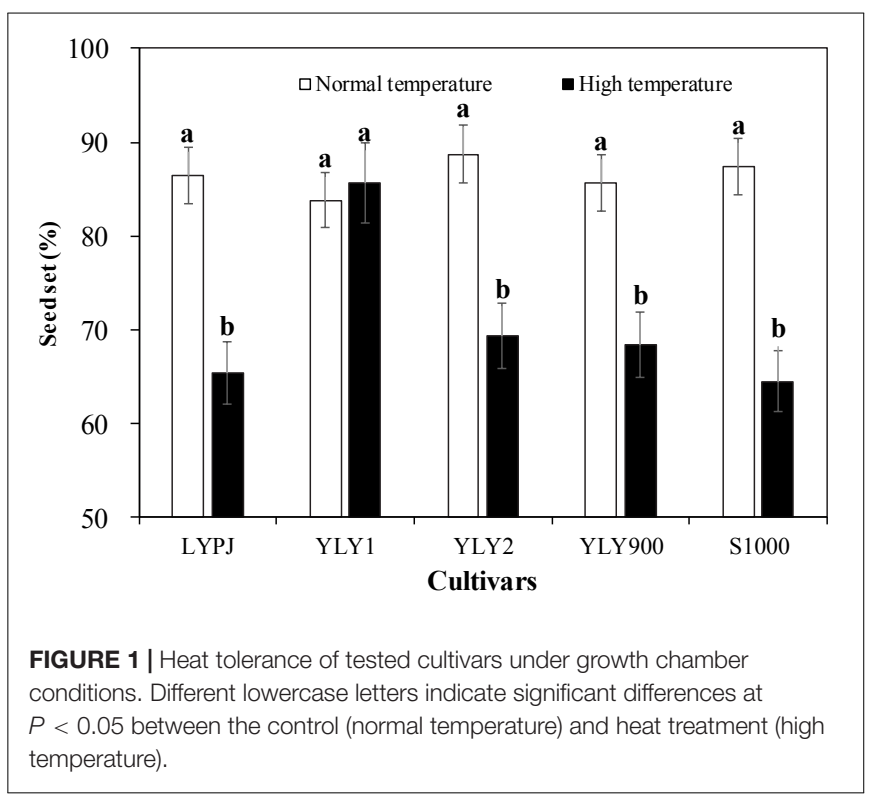





FIGURE 2 | (A) Seasonal mean temperature from June to September of 2001-2016. The dotted line is the average seasonal mean temperature; (B) Daily mean temperature and solar radiation from transplanting to maturity in 2015 and 2016. The red arrows indicate the flowering stage at Jingzhou in 2015 and 2016 ; (C) Average daily mean temperature during the flowering stage in 2015 and 2016; (D) Duration of temperatures $>35^{\circ} \mathrm{C}$ during the flowering stage in 2016 .

difference in average daily solar radiation between the 2 years during the growing season: seasonal average daily radiation was 15.7 $\mathrm{MJ} \mathrm{m}^{-2} \mathrm{~d}^{-1}$ in 2015 and $16.1 \mathrm{MJ} \mathrm{m}^{-2} \mathrm{~d}^{-1}$ in 2016. During the flowering stage, the daily highest temperature in 2016 was $36.9^{\circ} \mathrm{C}$, while it was only $33.3^{\circ} \mathrm{C}$ in 2015 (Figure 2C). There was a significant difference between the 2 years in the duration of temperatures exceeding $35^{\circ} \mathrm{C}$ during the flowering period. In 2015 there were no days with temperatures over $35^{\circ} \mathrm{C}$ during the flowering period. In 2016 , however, temperatures over $35^{\circ} \mathrm{C}$ were observed throughout the flowering period, lasting from 2 to $7 \mathrm{~h} \mathrm{~d}^{-1}$ (Figure 2D).

\section{Grain Yield, Seed-Set Percentage, and Spikelets per Panicle}

The ANOVA results for grain yield, seed-set percentage, and spikelets per panicle are shown in Table 3. Planting year (Y) had a significant effect on all parameters. Grain yields differed significantly $(P<0.01)$ among varietals $(V)$ and $N$ treatments $(T)$, but there were no significant differences in spikelets per panicle or grain filling between cultivars. The interaction effect of $\mathrm{Y} \times \mathrm{V}$ was significant $(P<0.01)$ for all parameters. Significant interaction effects of $Y \times T$ on grain yield and seed-set percentage were observed, and grain yield and spikelets per panicle were significantly $(P<0.01)$ affected by the interaction of $\mathrm{V} \times \mathrm{T}$. Interaction effects of $\mathrm{Y} \times \mathrm{V} \times \mathrm{T}$ were only significant for spikelets per panicle.

\section{Grain Yield Under Nitrogen Treatments in 2015 and 2016}

Due to the negative effects of high temperature during the flowering stage in 2016, grain yields of all cultivars except YLY1

TABLE 3 | Analysis of variance showing the effects of year, varietal, and $\mathrm{N}$ treatment on grain yield, grain filling, and spikelet per panicle.

\begin{tabular}{lccc}
\hline Source of Variance & Grain yield & Grain filling & Spikelet per panicle \\
\hline Year $(\mathrm{Y})$ & $*$ & $* *$ & $* *$ \\
Varietal $(\mathrm{V})$ & $* *$ & $\mathrm{~ns}$ & $\mathrm{Ns}$ \\
Treatment $(\mathrm{T})$ & $* *$ & $\mathrm{~ns}$ & $* *$ \\
$\mathrm{Y}$ V & $* *$ & $* *$ & $* *$ \\
$\mathrm{Y}^{*} \mathrm{~T}$ & $* *$ & $*$ & $\mathrm{Ns}$ \\
$\mathrm{V} * \mathrm{~T}$ & $* *$ & $\mathrm{~ns}$ & $* *$ \\
$\mathrm{Y} * \mathrm{~V} * \mathrm{n}$ & $\mathrm{ns}$ & $\mathrm{ns}$ & $* *$ \\
\hline
\end{tabular}

Ns, non-significant; * significant at $P<0.05,{ }^{* *}$ significant at $P<0.01$. 


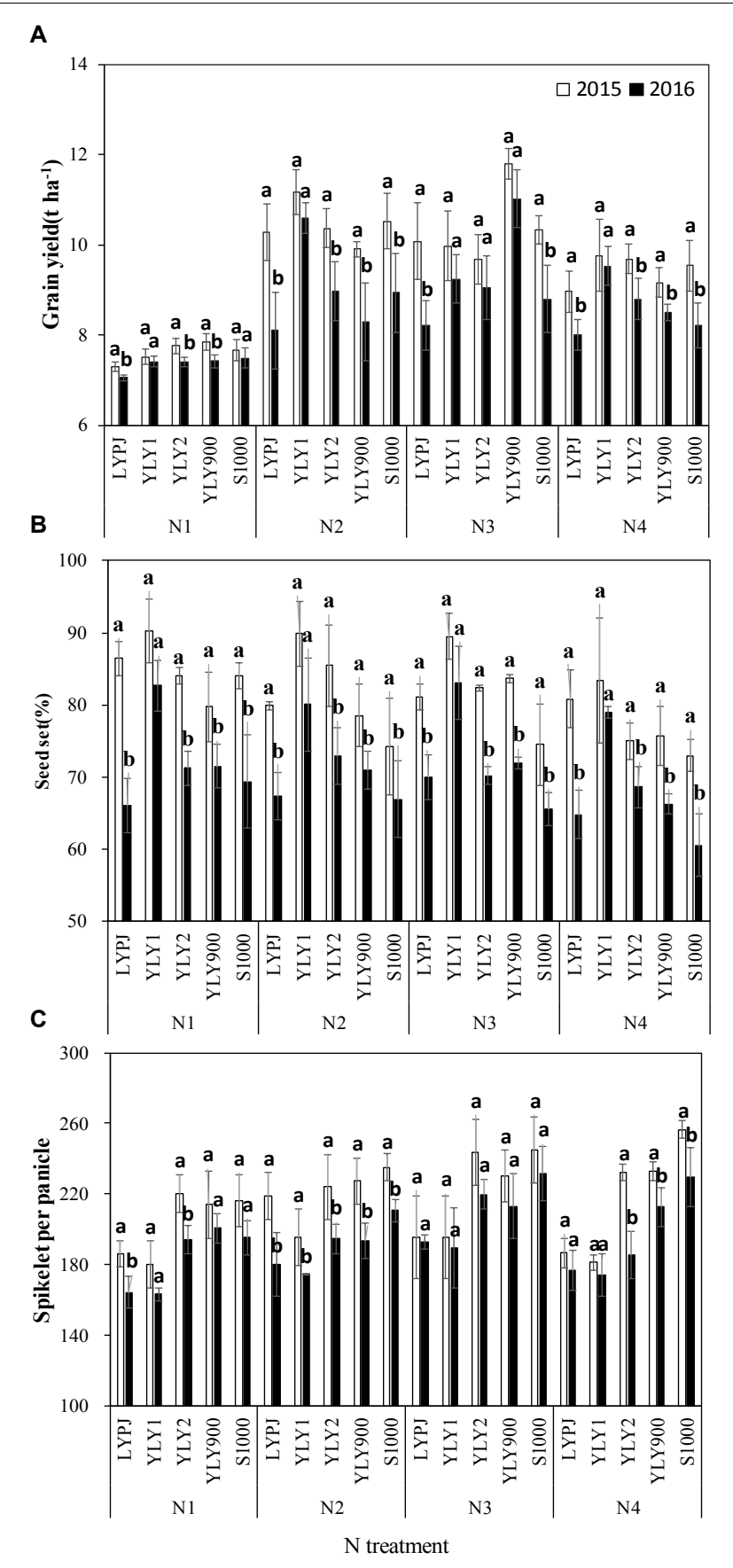

FIGURE 3 | Grain yield (A), grain filling (B), and spikelets per panicle (C) of five super hybrid rice cultivars grown under different $\mathrm{N}$ treatments in Jingzhou, Hubei Province, China, in 2015 and 2016. Data are the means of three replicates and the vertical bars represent the standard error. Different lowercase letters indicate significant differences $(P<0.05)$. The four $\mathrm{N}$ treatments were $0 \mathrm{~kg} \mathrm{ha}^{-1}$ (N1), $210 \mathrm{~kg} \mathrm{ha}^{-1}$ (N2), $300 \mathrm{~kg} \mathrm{ha}^{-1}$ (N3), and $390 \mathrm{~kg} \mathrm{ha}^{-1}$ (N4).

were significantly lower than those in 2015 under N1, N2, and N4 treatments (Figure 3A). For N3, some cultivars showed different response patterns to high temperature, and yield differences

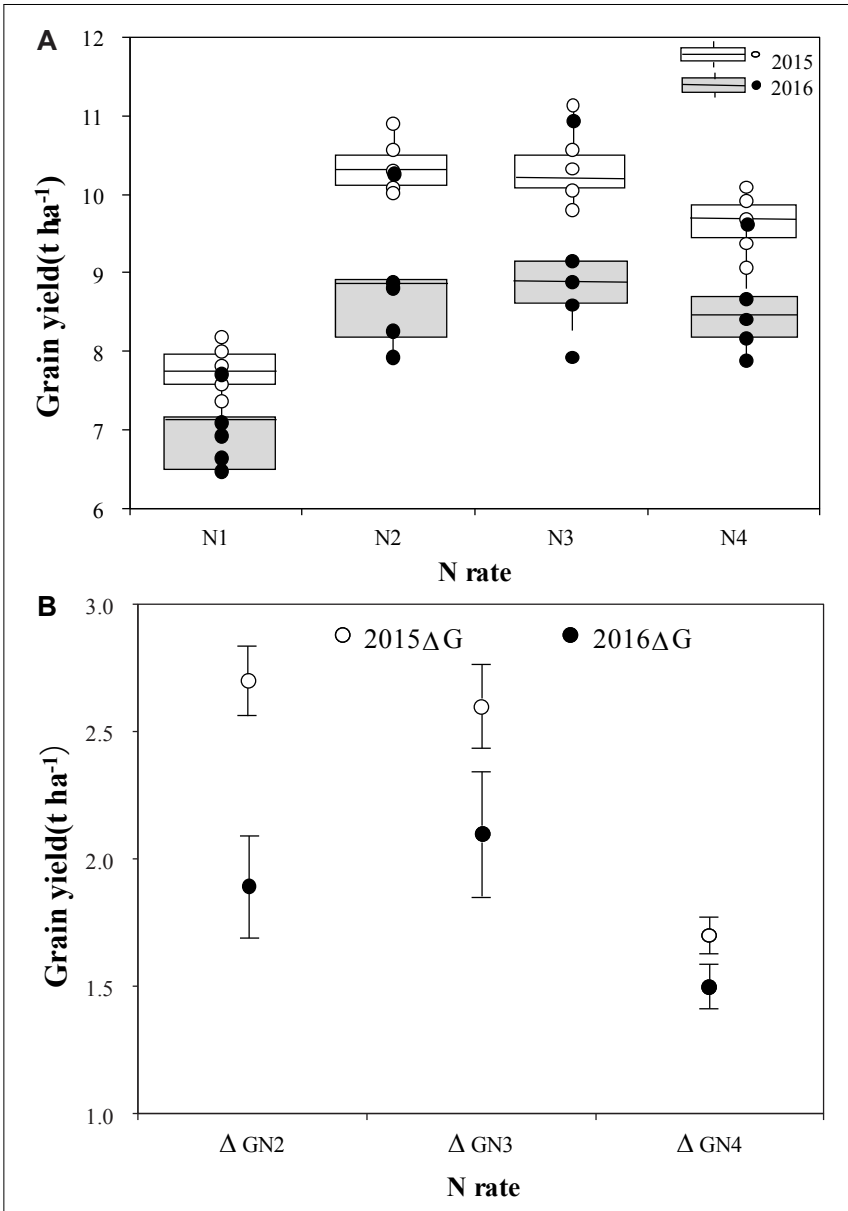

FIGURE 4 | Grain yield of five super hybrid rice cultivars under different N treatments in 2015 and 2016 (A), and average grain yields with grain yield production increase from using $\mathrm{N}(\triangle \mathrm{G})(\mathbf{B})$. The four $\mathrm{N}$ treatments were $0 \mathrm{~kg}$ $\mathrm{ha}^{-1}$ (N1), $210 \mathrm{~kg} \mathrm{ha}^{-1}$ (N2), $300 \mathrm{~kg} \mathrm{ha}^{-1}$ (N3), and $390 \mathrm{~kg} \mathrm{ha}^{-1}$ (N4).

between years were not significant in YLY1, YLY2, and YLY900. Compared with the grain yields in 2015, grain yields of LYPJ and S1000 decreased by 18.6 and $14.8 \%$, respectively, in 2016, while the range of annual yield differences in YLY1, YLY2, and YLY900 was only $6.5-7.3 \%$.

There were significant differences in grain yield between $\mathrm{N}$ treatments in 2015 and 2016 (Figure 4A). In 2015, the highest mean grain yield was $10.5 \mathrm{t} \mathrm{ha}^{-1}$ in the $\mathrm{N} 2$ treatment. As the $\mathrm{N}$ rates increased to $360 \mathrm{~kg} \mathrm{ha}^{-1}$ (N4), mean grain yield decreased to $9.4 \mathrm{t} \mathrm{ha}^{-1}$. Compared to grain yield in 2015, mean grain yields were much lower in 2016 for all $\mathrm{N}$ treatments. The mean grain yield was highest $\left(9.3 \mathrm{t} \mathrm{ha}^{-1}\right)$ in $\mathrm{N} 3$, followed by $8.9 \mathrm{t} \mathrm{ha}^{-1}$ in the $\mathrm{N} 2$ treatment. In 2015, the differences in grain yield among cultivars within $\mathrm{N}$ treatments were not significant, however, there were significant differences in 2016 when plants were exposed to high temperature stress during the flowering stage; the grain yield of YLY1 was significantly higher than that of the other four cultivars. The difference between years in the production increase with $\mathrm{N}$ treatment was also significant $(P<0.05)$ (Figure 4B). The gap in 
$\Delta \mathrm{G}$ between the 2 years decreased with an increase in $\mathrm{N}$ application rate; the yield difference in $\Delta G_{N 2}$ was the highest $\left(0.8 \mathrm{~kg} \mathrm{ha}^{-1}\right)$, and it was only $0.5 \mathrm{~kg} \mathrm{ha}^{-1}$ in $\Delta \mathrm{G}_{\mathrm{N} 4}$ and $0.2 \mathrm{~kg} \mathrm{ha}^{-1}$ in $\Delta \mathrm{G}_{\mathrm{N} 3}$.

\section{Seed-Set Percentage and Spikelets per Panicle Under Nitrogen Treatments in 2015 and 2016}

High temperatures during the flowering stage significantly reduced the seed-set percentage of these cultivars (Figure 3B). Seed-set percentage in these cultivars, except in YLY1, was significantly lower in 2016 than in 2015. Increasing $N$ resulted in a decrease in seed-set percentage. LYPJ was the most sensitive to heat stress, and its seed-set percentage decreased much more than that of the other cultivars with $\mathrm{N}$ treatments. The number of spikelets per panicle was significantly affected by the high temperature in 2016 (Figure 3C). Spikelets per panicle showed different responses to high temperature among $\mathrm{N}$ treatments. The differences in spikelets per panicle between years under $\mathrm{N} 1$ and $\mathrm{N} 2$ were much higher than those under N3 and N4. Compared with 2015, the spikelets per panicle decreased by 9.8 and $13.4 \%$ under $\mathrm{N} 1$ and $\mathrm{N} 2$, respectively, while it was only 5.4 and $7.6 \%$ under N3 and N4, respectively. The number of spikelets per panicle saw a significant increase under N3 in some cultivars, and there was no significant difference in spikelets per panicle between the 2 years.

\section{Correlations Between Grain Yield, Seed-Set Percentage, Spikelets per Panicle, and Nitrogen Treatment}

There was a significant $(P<0.01)$ positive correlation between grain yield and $\mathrm{N}$ treatment, but no significant relationship was observed between seed-set percentage and $\mathrm{N}$ treatment (Figure 5). Grain yield $(P<0.01)$ and spikelets per panicle $(P<0.05)$ were positively correlated with $\mathrm{N}$ treatment in 2016.

\section{DISCUSSION}

Previous studies have reported the effects of high $\mathrm{N}$ levels on grain yields, under high-temperature stress (Duan et al., 2013; Yang et al., 2014). However, the results of these studies were obtained from climate chamber experiments, rather than field conditions. The responses of plants grown in the field can be very different from those in climate chambers (Chen et al., 2003). Therefore, these previous findings have limitations.

In our study, we compared the yields of super rice cultivars under different $\mathrm{N}$ treatments between 2 years in a field experiment. Because of a reduction in seed-set percentage caused by high temperature during the flowering stage, mean grain yield in 2016 was significantly lower than that in 2015. Despite the negative effect of high temperature, a lower proportion of yield loss was observed in those cultivars treated with higher levels of $\mathrm{N}$ (N3 or N4) than those in N1 or N2 treatments (Figure 2A); there were minor differences between $\Delta \mathrm{G}_{\mathrm{N} 3}$ and $\Delta \mathrm{G}_{\mathrm{N} 4}$. Our

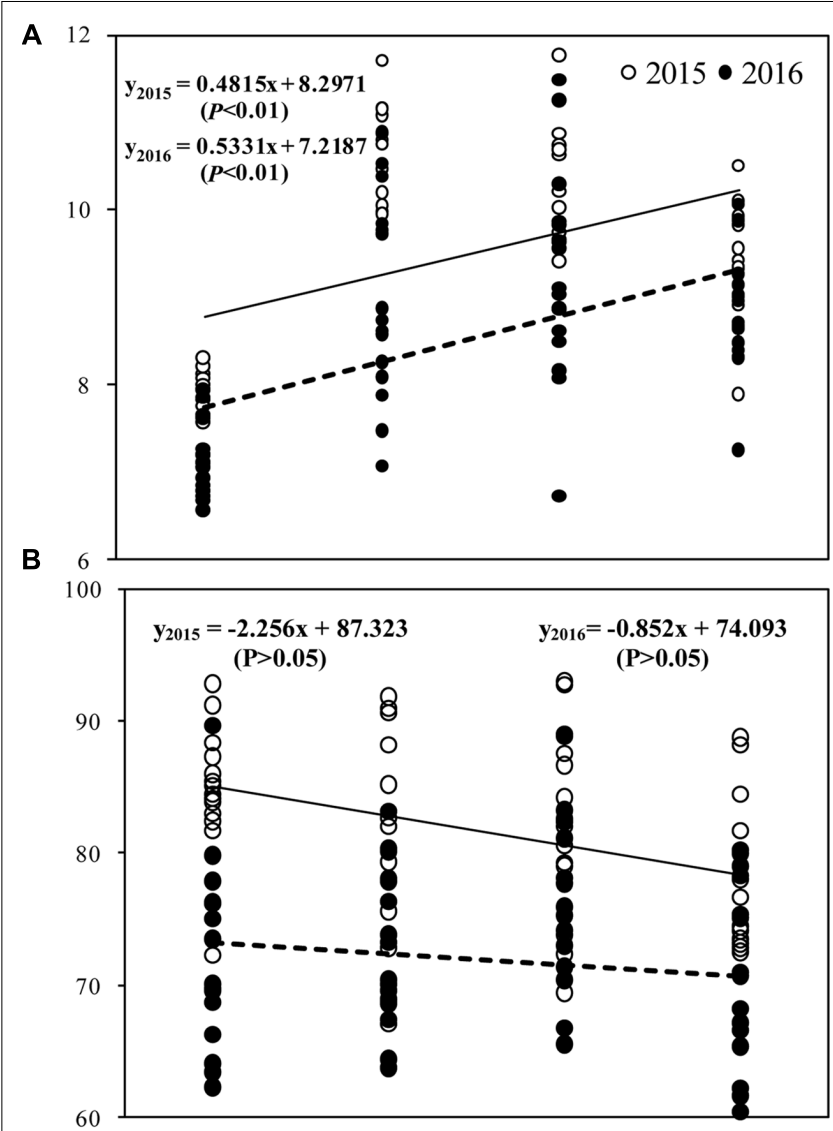

C

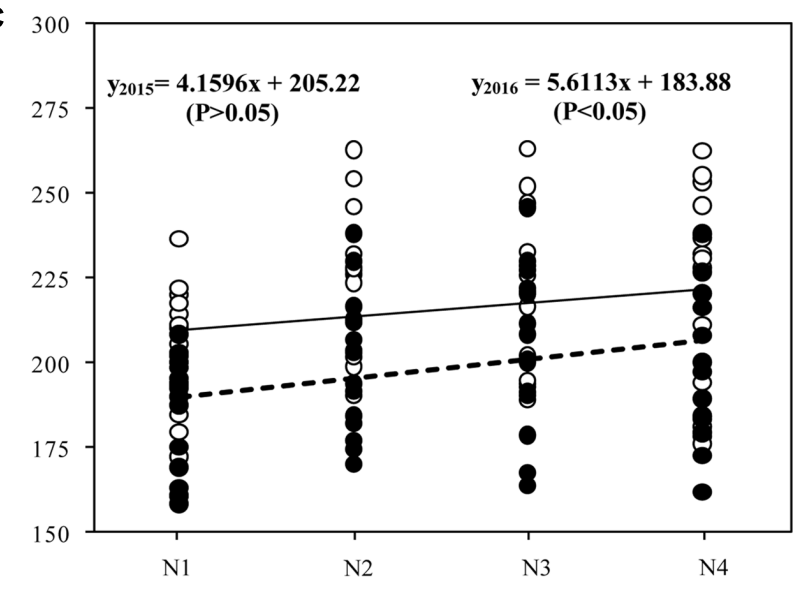

FIGURE 5 | Correlation between grain yield (A), grain filling (B), spikelet per panicle (C), and $\mathrm{N}$ treatments in 2015 and 2016. The four $\mathrm{N}$ treatments were $0 \mathrm{~kg} \mathrm{ha}^{-1}$ (N1), $210 \mathrm{~kg} \mathrm{ha}^{-1}$ (N2), $300 \mathrm{~kg} \mathrm{ha}^{-1}$ (N3), and $390 \mathrm{~kg} \mathrm{ha}^{-1}$ (N4).

field results suggest that high $\mathrm{N}$ levels can positively affect grain yield when rice plants are exposed to high temperatures at the flowering stage.

However, Shi et al. (2017) argued that increasing total $\mathrm{N}$ did not alleviate the effects of high night temperatures on rice yields. This result may be due to the different varietals used. Heattolerant cultivars like YLY1 did not show significant differences 
between $\mathrm{N}$ treatments when exposed to high temperature, which suggests that some cultivars may not benefit from high $\mathrm{N}$ application to address yield loss caused by high-temperature stress. For other heat-sensitive cultivars, yield loss could be reduced by increasing $\mathrm{N}$ application rates. The yield performance of these heat-sensitive cultivars showed similar trends under high $\mathrm{N}$ levels when they were exposed to high-temperature stress in our study. Compared with the inbred cultivars used in Shi et al.'s (2017) experiment, the super hybrid rice cultivars in our study had larger panicles with numerous spikelets per panicle and high biomass production, and hence, required a large amount of $\mathrm{N}$ fertilizer input to achieve high yields. Varietal differences may, therefore, be responsible for the differences in results between studies.

The most recently released super hybrid rice cultivars have a large number of spikelets on a panicle, with a large yield potential (Yuan, 2017). However, these elite cultivars in our study did not show as high a seed-set percentage ratio as expected, even under normal conditions. Yang and Zhang (2009) argued that because of poor grain filling of later-flowering inferior spikelets (compared with the earlier-flowering superior spikelets), super hybrid rice fails to achieve its high yield potential. In our study, mean seedset percentage in 2016 was $13.0 \%$ lower than that in 2015 at higher $\mathrm{N}$ levels but only $9.6 \%$ lower at lower $\mathrm{N}$ levels. These results suggest that higher $\mathrm{N}$ input may exacerbate a decrease in seed-set percentage of super hybrid rice cultivars under high temperature.

Prior to this study, few field experiments have attempted to elucidate the mechanism by which $\mathrm{N}$ management could alleviate the damaging effects of high temperature on rice grain yield. Previous studies conducted using controlled temperature chambers showed that high $\mathrm{N}$ fertilizer application could contribute to improvements in the number of panicles, spikelets per panicle, or grain weight in plants under high-temperature stress. Possible mechanisms could be a higher photosynthetic rate in flag leaves, greater root oxidation activity, or crucial enzymes involved in the sucrose-to-starch metabolic pathway in grains (Duan et al., 2013). However, in this study, no significant differences in grain weight or panicle numbers were observed (data not shown) across 2 years under different $\mathrm{N}$ treatments. The differences between studies may be attributable to the timing of the high temperatures. In our study, high temperature occurred during the flowering stage.

\section{REFERENCES}

Bheemanahalli, R., Sathishraj, R., Tack, J., Nalley, L. L., Muthurajan, R., and Jagadish, K. S. V. (2016). Temperature thresholds for spikelet sterility and associated warming impacts for sub-tropical rice. Agric. Forest Meteorol. 221, 122-130. doi: 10.1016/j.agrformet.2016.02.003

Chen, Y., Murchie, E. K., Hubbart, S., Horton, P., and Peng, S. (2003). Effects of season-dependent irradiance levels and nitrogen-deficiency on photosynthesis and photoinhibition in field-grown rice (Oryza sativa). Physiol. Plant 117, 343-351. doi: 10.1034/j.1399-3054.2003.00048.x

Cheng, S. H., Cao, L. Y., Zhuang, J. Y., Chen, S. G., Zhan, X. D., Fan, Y. Y., et al. (2007). Super hybrid rice breeding in China: achievements and prospects. J. Int. Plant Biol. 49, 805-810. doi: 10.1111/j.1744-7909.2007. 00514.x
It should be noted that relatively higher numbers of spikelets per panicle were observed in those cultivars exposed to high temperature and higher $\mathrm{N}$ application levels than those at lower $\mathrm{N}$ levels (Figures $\mathbf{3 A}, \mathbf{B}$ ). The reason for this finding may be related to a higher number of primary and secondary branches. Liu et al. (2005) reported that primary and secondary branch differentiation was prolonged by higher $\mathrm{N}$ levels, and the number of branches increased accordingly, leading to an increase in maximum differentiated floret number per panicle. In the 2 years of our study, a larger amount of $\mathrm{N}$ was applied at panicle initiation in higher $\mathrm{N}$ treatments than in lower $\mathrm{N}$ treatments. Zhou et al. (2017) argued that postponing $\mathrm{N}$ application could reduce the degenerated number of secondary branches and increase the differentiation of spikelets, thus leading to an increase in the number of spikelets per panicle. In our study, spikelets per panicle was significantly related to $\mathrm{N}$ level and temperature $(P<0.01)$. Higher $\mathrm{N}$ levels may inhibit the number of degenerated spikelets under high temperature. Therefore, it seems that production of a higher number of spikelets per panicle is the key factor that contributes to reducing yield loss under high temperature by increasing $\mathrm{N}$ application levels.

\section{AUTHOR CONTRIBUTIONS}

$\mathrm{YZ}$ and $\mathrm{KL}$ initiated and designed the research, analyzed the data, and wrote the manuscript. KL, JD, and JL performed the experiments. XW, BL, and XT revised and edited the manuscript and also provided advice on the experiments.

\section{FUNDING}

We are grateful for grants from the National Key Research and Development Program of China (2016YFD0300108), and the fund for Yangtze Youth Teams of Science and Technology Innovation (2015cqt02).

\section{ACKNOWLEDGMENTS}

We are grateful to Yangtze University Excellent Doctoral Dissertation Development Program.

Dai, Y., Ding, Y., Wang, Q., Li, G., Liu, Z., and Wang, S. (2009). Effect of high daytime temperature on rice quality under different panicle nitrogen treatments. Plant Nutri. Fertil. Sci. 15, 276-282.

Duan, H., Fu, L., Ju, C., Liu, L., and Yang, J. (2013). Effects of application of nitrogen as panicle-promoting fertilizer on seed setting and grain quality of rice under high temperature stress. Chin. J. Rice Sci. 27, 591-602.

Farrell, T. C., Fox, K. M., Williams, R. L., and Fukai, S. (2006). Genotypic variation for cold tolerance during reproductive development in rice: screening with cold air and cold water. Field Crops Res. 98, 178-194. doi: 10.1016/j.fcr.2006.01.003

Food and Agriculture Organization [FAO] (2010). FAOSTAT Database 2010. Available at: http://www.fao.org/faostat/en/\#home [accessed July 14, 2010].

Intergovernmental Panel on Climate Change [IPCC] (2013). "Climate change 2013: the physical science basis," in Contribution of Working Group I to the Fifth Assessment Report of the Intergovernmental Panel on Climate Change, eds 
T. F. Stocker, D. Qin, G.-K. Plattner, M. Tignor, S. K. Allen, J. Boschung, et al. (Cambridge: Cambridge University Press).

Jagadish, S. V. K., Craufurd, P. Q., and Wheeler, T. R. (2007). High temperature stress and spikelet fertility in rice (Oryza sativa L.). J. Exp. Bot. 58, 1627-1635. doi: 10.1093/jxb/erm003

Jagadish, S. V. K., Muthurajan, R., Oane, R., Wheeler, T. R., Heuer, S., Bennett, J., et al. (2009). Physiological and proteomic approaches to address heat tolerance during anthesis in rice (Oryza sativa L.). J. Exp. Bot. 61, 143-156. doi: 10.1093/ jxb/erp289

Kim, J., Shon, J., Lee, C. K., Yang, W., Yoon, Y., and Yang, W. H. (2011). Relationship between grain filling duration and leaf senescence of temperate rice under high temperature. Field Crops Res. 122, 207-213. doi: 10.1016/j.fcr. 2011.03.014

Liu, K., Wang, X. Y., Lu, B. L., Tian, X. H., Punzalan, B., Laza, R., et al. (2017). Effects of high night temperature on grain quality under field chamber system condition. Philipp. J. Crop Sci. 3, 56-62.

Liu, X. W., Meng, Y. L., Zhou, Z. G., and Cao, W. X. (2005). Dynamic characteristics of floret differentiation and degeneration in rice. Acta Agron. Sin. $31,451-455$.

Lu, R. (1999). K. Soil Agrochemistry Analysis Protocols. Beijing: China Agriculture Science Press.

Matsui, T., Kobayasi, K., Kagata, H., and Horie, T. (2005). Correlation between viability of pollination and length of basal dehiscence of the theca in rice under a hot-and-humid condition. Plant Prod. Sci. 8, 109-114. doi: 10.1626/ pps.8.109

Matsui, T., and Omasa, K. (2002). Rice (Oryza sativa L.) cultivars tolerant to high temperature at flowering: anther characteristics. Ann. Bot. 89, 683-687. doi: $10.1093 / \mathrm{aob} / \mathrm{mcf1} 12$

Mu, Q., Zhang, W., Zhang, Y., Yan, H., Liu, K., Matsui, T., et al. (2017). iTRAQbased quantitative proteomics analysis on rice anther responding to high temperature. Int. J. Mol. Sci. 18:E1811. doi: 10.3390/ijms18091811

Peng, S., Khush, G. S., Virk, P., Tang, Q. Y., and Zou, Y. B. (2008). Progress in ideotype breeding to increase rice yield potential. Field Crop Res. 108, 32-38. doi: 10.1016/j.fcr.2008.04.001

Piao, S., Ciais, P., Huang, Y., Shen, Z., Peng, S., Li, J., et al. (2010). The impacts of climate change on water resources and agriculture in China. Nature 467, 43-51. doi: 10.1038/nature09364

Satake, T., and Yoshida, S. (1978). High temperature induced sterility in indica rices at flowering. Jap. J. Crop Sci. 47, 6-17. doi: 10.1626/jcs.47.6
Seck, P. A., Diagne, A., Mohanty, S., and Wopereis, M. C. (2012). Crops that feed the world 7: rice. Food Sec. 4, 7-24. doi: 10.1007/s12571-012-0168-1

Shi, W., Xiao, G., Struik, P. C., Jagadish, K. S. V., and Yin, X. (2017). Quantifying source-sink relationships of rice under high night-time temperature combined with two nitrogen levels. Field Crops Res. 202, 36-46. doi: 10.1016/j.fcr.2016. 05.013

Tian, X., Luo, H., Zhou, H., and Wu, C. (2009). Research on heat stress of rice in China: progress and prospect. Chin. Agric. Sci. Bull. 25, 166-168.

Waraich, E. A., Ahmad, R., Halim, A., and Aziz, T. (2012). Alleviation of temperature stress by nutrient management in crop plants: a review. J. Soil Sci. Plant Nutr. 12, 221-244. doi: 10.4067/S0718-95162012000200003

Yan, C., Ding, Y., Wang, Q., Li, G., Liu, Z., Miao, X., et al. (2008). Effect of panicle fertilizer application rate on morphological, ecological characteristics, and organ temperature of rice. Acta Agron. Sin. 34, 2176-2183. doi: 10.3724/SP. J.1006.2008.02176

Yan, H. L., Zhang, B., Zhang, Y., Chen, X., Xiong, H., Matsui, T., et al. (2017). High temperature induced glume closure resulted in lower fertility in hybrid rice seed production. Front. Plant Sci. 7:1960. doi: 10.3389/fpls.2016.01960

Yang, J., Chen, X., Zhu, C., Peng, X., He, X., Fu, J., et al. (2014). Effects of nitrogen level and high temperature at late booting stage onyield and physiological characteristics of two early rice cultivars. Chin. J. Rice Sci. 28, 523-533.

Yang, J., and Zhang, J. (2009). Grain-filling problem in 'super' rice. J. Exp. Bot. 61, 1-5. doi: $10.1093 / \mathrm{jxb} / \mathrm{erp} 348$

Yuan, L. P. (2017). Progress in super-hybrid rice breeding. Crop J. 5, 100-102. doi: 10.1016/j.cj.2017.02.001

Zhou, W., Lv, T., Yang, Z., Wang, T., Fu, Y., Chen, Y., et al. (2017). Morphophysiological mechanism of rice yield increase in response to optimized nitrogen management. Sci. Rep. 7:17226. doi: 10.1038/s41598-017-17491-y

Conflict of Interest Statement: The authors declare that the research was conducted in the absence of any commercial or financial relationships that could be construed as a potential conflict of interest.

Copyright $\odot 2019$ Liu, Deng, Lu, Wang, Lu, Tian and Zhang. This is an open-access article distributed under the terms of the Creative Commons Attribution License (CC BY). The use, distribution or reproduction in other forums is permitted, provided the original author(s) and the copyright owner(s) are credited and that the original publication in this journal is cited, in accordance with accepted academic practice. No use, distribution or reproduction is permitted which does not comply with these terms. 